\title{
PREVENTION OF
}

ADOLESCENT SUICIDE

\author{
A Seminar Paper \\ Fresented to \\ the Graduate Faculty \\ University of Hisconsin - Ia Crosse
}

In Partial Fulfillment

of the Requirements for the Degree

Master of Science in Education: Special Education

by

Donna I. Callies

May 1984 
Table of Contents

Chapter

Page

I. Introduction .................... 1

II. Review of Literature . . . . . . . . . . . 4 4

Variables that Contribute to Adolescent Suicide. . . 4

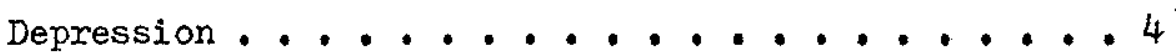

Family relations ............. 6

Social relations . . . . . . . . . . 7

School failure ............. 8 .

Waming Signs of Suicidal Ideation . . . . . . . 8

Overt waming signs.............. 8

Lethality. . . . . . . . . . . . . 11

Assessment Devíces . . . . . . . . . 12

III. Interpretation of Iiterature Review. . . . . . 15

IV. Implications and Action Plan ........... 17

School involvement ........... 17

Inservice training . . . . . . . . 18

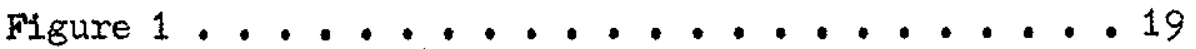

Alternative interventions. . . . . . . 20

Summary Statement. . . . . . . . . 20

References cited ........... 21 21

Appendices . . . . . . . . . . 25 
Abstract

The purpose of this study was to review relevant literature concermed with adolescent suicide. The incidence of adolescent sulcide was examined as well as literature dealing with causation, depression, family relations, social relations, and school failure. Overt warning signs were presented and discussed along with a review of the lethality of the sulcidal ideation and intent. An action plan was proposed which consisted of a plan for a unified school program to address the issue of adolescent suicide, an outline of an inservice training program for concerned teachers, and a provision for contacting consultants in the community when the problem of suicide becomes too great for educators to handle effectively. Included was a packet of material to be distributed for inservice training of concermed teachers. 
Chapter I

Introduction

Adolescient: sulcide is at an epidemic: level today. Studies have shown that from 1974-1975, the suicide rate of the 15-19 ase group increased 124\% (McBrien, 1983). The New Jexsey Education Association Review (NJEAR) reported thati in 1980, the teenager suicide rate had increased $200 \%$ since 1950 . In the United States alone, suicide has become the third leading cause of death among adolescents (Emery, 1983; Smith, E. J., 1981). In 1971, 3,479 youths between the ages of 15-24 were reported to have committed suicide. In 1975 , 4,870 youths in the same age group committed suicide (Hart, 1978; Rosenkrantz, 1978). In 1978, 5,000 children and adolescents comitted sulcide, or nearly three times the number that did so 20 years ago. Within the last 10 years, the suicide rate for teenagers has almost doubled; it is estimated that 57 teenagers attempt suicide every hour (Smith, E. J., 1981). In 1979 the number of deaths by suicide for the 15-24 age group of white males was $21.0 \%$, or nearly 5,000 deaths per 100,000 deaths (Statistical Abstracts of the Unted States, 1982-1983).

The number of adolescent deaths caused by suicide may be underestimated. Statistics become "meaningless" because of heavy underreporting (Emexy, 1982). A death is recorded statistically 
as a suicide only when it is signed on the death certificate as

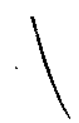
such (Hart, 1978). There is no uniform legal requirement for reporting a death by sulcide, which suggests that many deaths may be attributed to other causes (Smith, D. F., 1976). Shaffer. and Fisher (1981) reported that in 1968 a new label for a cause of death was introduced and incorporated in the Intemational Classification of Diseases: "undetermined whether death is accidental or purposefully inflicted"'. The number of deaths of teenagers attributed to suicide does not include children under 10, whose deaths are classified as accidents. The numbers also do not include drug overdoses, willful accidents, or even some homicides where the suicidal person angers another person in the hope that this will lead to a fight and ultimately to the teenager.'s death (Hart, 1978 ; Smith, E. J., 1981; Toolan, 1962).

Taken all together, the number of actual completed suicides by adolescents is much higher than statistics or authors report. It is conservatively estimated that for every one completed suicide, there are approximately 10 attempts (Emery, 1983). More liberal estimates state that for every one successful suicide, there are 50-150 suicide attempts (McBrien, 1983).

Young people today are choosing suicide as a means of escaping the many problems and frustrations they face. Many authors have cited family problems such as parental pressure to succeed, parental divorce and remarriage, transient families or death of one or both parents as the major cause of adolescent suicide (Emery, 1983; Greuling \& DeBlassie, 1980; Klagsionun, 1977; McBrien, 1983; 
PInkston, 1983; Smith, D. F., 1976; Smith, E. J., 1981). The authors cited have listed other factors which have been reported by teenagers as having the potential to lead them to contemplate and attempt suictde. These factors included: depression; drug and alcohol temptations; boy or girlfriend problems; fear of failure; lack of love; rejections; the so-called allenation of youth; and peer pressure and conflicts.

As educators who work with a special population of students where school and home problems may be of greater intensity, teachers must become aware of the causes and warning signs of adolescent suicide, and be prepared to offer preventive strategies to reverse the rising number of young people who take their own lives. In order to insure that teachers can recognize causes of adolescent suicide and sulcidal signs, and offer positive interventions, this paper attempted; (a) to identify variables that contribute to adolescent suicide; (b) to identify overt waming signs of adolescent suicide; (c) to examine assessment devices which are most successful in identifying the potential of suicide; and (d) to propose an intervention strategy to be implemented in school. 
Chapter II

Review of Literature

The review of literature chapter served three purposes. The first section of the chapter discussed Ldentified variables that contribute to adolescent suicide. The major subtopics in this section were, depression; family relations; social relations; and school fallure. The second section of the chapter discussed identified overt warning signs, ranging from low lethality signs to high lethality signs. The third section reviewed four assessment devices to determine lethality.

\section{Variables that Contribute to Adolescent Suicide}

Depression. To assess the correlation between depresston and suicide attempts, Carison and Cantwell (1982) conducted a study with 102 consenting adolescents, who were psychiatrically referced because of suicidal ideation and depression, and their parents to determine the relationship between sulcide and depression. The study examined:

(1) the extent to which psychiatrically referred children who contemplate sufcide are depressed; (2) if children who actually attempt suicide are more depressed than those who simply think about it; (3) which specific psychiatric diagnoses are most associated with suicide behavior; (4) whether feelings 
Shaffer (1982) reported that a study conducted at Children's Hospital National Medical Center in Washington showed that a group of 20 children with suicidal behavior were more often depressed than their nonsuicidal comparison group of 21 children.

A survey of high school professionals by Grob, Klein, and Eisen (1983) indicated that $70 \%$ of teachers surveyed felt that depression was an indicator of suicidal risk for adolescents. Smith, E. J. (1981) reported depression to be a major factor in adolescent suicides. In a study reported by McBrien (1983) with a group of 40 adolescents who had all attempted suiclde, $82 \%$ of the group were severely depressed.

Family relations. Family problems have been identified by Konopka, McBrien, Pinkston (1983), and Smith, E. J. (1981) as being a predominant factor in suicide attempts by teenagers. McGulre (1982) cited that continual parent-child fighting resulted in a crippling environment that may lead to suicide by the child. Disruptions in family life due to divorce or death, alcoholism, or poverty because of the sudden loss of employment precipitated adolescent suicide.

Pfeffer, Solomon, Plutchik, Mizruchi, and Weiner (1982) isolated factors related to the number of children and the child's ordinal position in the family, parental violence, and divorce as variables that contributed to adolescent suicide. Also, the attempted suicides of parents influenced children to attempt suicide. Peck (1982) emphasized the destructiveness of divorce 
on a teenager, which resulted in suicide. Pfeffer (1981) reported parental separation, marital discord, and abuse and neglect may be associated with sulcidal behavior of children. Grueling and DeBlassie (1980) reported that a significantly high proportion of adolescents attempting sulcide experienced the death of a parent. According to Lee (1978) the child may view a parental death as abandonment, and the result is that the child internalizes hostility toward the deceased parent and the culmination of the hostility is suicide by the teenager.

The ambivalence demonstrated by the family towards the child can push the child to suicide as an escape (Smith, E. J., 1981). Researchers have discovered that young people need a warm, loving family environment, need to be treated equally and be viewed as a significant family member. When this is lacking, the teenager may eventually commit suicide (Konopka, 1983; McAnarney, 1979).

Social relations. Adolescence is a time when a person's body is changing very rapidly; developing satisfactory relationships with other adolescents is very important. The failure to be accepted by a peer group may result in suicide (Hart, 1978; Konopka, 1983; Pinkston, 1983). Boy or glrlfriend problems are also related to adolescent suicide, where one teenager is rejected by the other teenager (Pinkston, 1983).

In a study conducted by Henz (1979) with 200 subjects who etther had a history of previous suicide attempts or a history of calls to crisis-intervention centers, Henz used Dean's Alienation Scale 
to determine what variable(s) were associated with alienation. The results indicated that the strongest variable associated with alienation was lack of social contact with peers.

Peck (1982) reported the absence of a close friend, with whom to share problems, may be the difference between living or taking one's life. Peck stated, "if the history of the youngster is one of progressive or continued isolation in early chilahood, the prognosis for suicide is more serious than if the history indicates the ability to have some relationships" (p. 35).

School failure. Much pressure is placed on adolescents to achieve in school today. Fafluxe to achieve both intrapersonal and intexpersonal goals may effect some adolescents severely. Regardless of one's age, fallure can lead to suicidal attempts and completion of the act (Pinkston, 1983; Smith, E. J., 1981). School performance has been reported as almost uniformly poor in adolescent suicides. These students had a tendency to be truant more often, were more of a discipline problem, and were dropping out of school at the time of sulcidal attempts (Smith, D. F., 1976).

Harning Signs of Suicidal Ideation

Overt warning signs. Many authors and researchers have identified certain behaviors which have become associated with suicidal ideation of adolescents. McKenry, Tisher, and Christman (1980), Morgan (1981), and Smith, D. F. (1976) provided information about behavioral changes or cues which are indicators of suicidal thought. 
This list included: (a) a drastic change in the students's personal appearance, particularily from good to bad; (b) somatic complaints; (c) Inability to concentrate and problems in judgement and memory; (d) a dramatic shift in quality of school work; and (e) changes in daily behavior and living patterns, such as extreme fatigue, boredom, stammering and/or decreased appetite. Social behavior changes included: (a) behavioral disorders in class; (b) falling asleep in class;

(c) emotional outbursts compounded with crying or laughter; (d) inability to sit still; (e) sudden bursts of energy followed by lethargy; (f) excessive use of alcohol or drugs; (g) open signs of mental illness, such as delusions and hallucinations; ( $h$ ) a sense of overwhelming guilt and shame; and (i) loss of friends.

The NJEAR (1982) and Smith, E. J. (1981) also identified signs of suicide contemplation: (a) changes in sleeping or eating habits; (b) a signiflcant decline in school performance along with giving away prized possessions; (c) having a preoccupation with death, and (d) making statements about feeling worthless or being: a burden to the family. McBrien (1983) has ldentified four broad areas that are signs that a teenager may be thinking about suicide: 1. verbal statements such as, "I want to die"; 2 . behavioral clues, the most serious being previous attempts or writing a will; 3. situational clues, with family and relationship problems being most common; and 4. syndromatic clues, with the three developmental stages of the syndrome being (a) history of previous problems, (b) additional problems being associated 
with adolescense, (c) a recent intense period of problems with significant social relationships. (p. 76) McGuire (1982) Ilsted the following as posstble presulcidal behavioxs; (a) running away from home; (b) accident proneness; (c) impulsive acting out; (d) temper tantrums; (e) self-deprecation; (f) serious conflict; (g) loneliness: (h) aggressions, external and inhibited; (i) changes in school performance; and (j) psychosomatic illnesses. Behaviors such as excessive risk-taking, along with acting irrationally where such behaviors had not been present in the past, may be indicators of adolescent suicidal ideation (temery, 1983; Grob, et al., 1983; Hart, 1978).

Besides being aware of behaviors in the school or classroom, teachers must also be aware of problems that may be effecting teenagers away from school, particularily at home. McKenry, Tisher, and Christman (1980) provided a list of major causes of suicide away from school which included, (a) the death of a famliy member, close friend or relative; (b) the divorce or separation of parents, siblings or relatives; (c) personal problems with the law or a family nember who is having present difficulty with the law; (d) the marriage of a stbling or remarriage of a parent; (e) a change in residence; (f) trouble with a teacher or teachers or a parent having trouble with a boss at work; and $(g)$ the death of a pet. The prescence of these crises did not necessarily imply suicldal thoughts, but if teachers were aware of these happenings away from school, along with changes in behavioral patterns, teachers stood a better chance of 
preventing an adolescent suicide if one was being contemplated. A summarization of overt behaviors associated with impending suicide can be found in Appendix A.

Lethality. Any expression of a suicide threat should be taken seriously by teachers. The thought of suicide is recognized as a cry for help. When a teenager displays one or more of the warning signs of suicide, the first step a teacher must take is to determine the lethality of the sulcide intent. Smith, E. J. (1981) has divided lethality into three groups:

1. high lethality - the person definitely wants to die and anticipates that his or her actions will result in death; 2. medium lethality - the person is ambivalent, playing some partial or unconscious role, as in drug abuse, foolhardiness, carelessness or outright disregard of lifesaving medical care; and 3. low lethality - the person has no conscious which to die and yet is willing to take unknown risks, as in the case of "inhalers". (p. 291)

Teachers determined which level of lethality the teenager was experiencing by being aware of the teenagex's suicidal history, suictal plan, resources that the adolescent had avallable to prevent a suicide attempt, and communication avenues open to the youth. Assessment of lethality helped the concerned teacher to judge as accurately as possible how likely an identified student was to attempt suicide in the immediate future. $\times$ By assessing lethality teachers had a basis for planning interventions, for discriminating 
potential lethal adolescent suicide attempts from "non-serious" adolescent sulcide attempts, and to help the teacher deal with anxieties regarding the potential suicide of another person (Motto, 1978; Smith, E. J., 1981).

\section{Assessment Devices}

Once a student approaches a teacher about suicidal thoughts, or has been identified as possibly committing suicide, the teacher has available a number of devices to assess the lethality of the suicidal thoughts, and devices which may help the teenager reflect on what has been comtemplated, and change their thoughts. Nelson and chiles (1983) have developed a theasons for living Inventory (RFL) (Appendix B). The RFI was tested on 197 Seattile shoppers and 175 psychiatric inpatients. Six categories containing statements to which the subjects gave a yes or no answer were (a) Survival and Coping Beliefs; (b) Responsibility to Family; (c) Child-Related Concerns; (d) Fear of Sulcide; (e) Fear of Soctal Disapproval; and (f) Moral Objections. After tallying the responses, those with higher sulcidal ideation had a lower amount of yes responses to all statements. The RFL has been shown to be an effective tool to assess the degree of lethality an adolescent has experienced. The Hopelessnests Scale (HS) (Appendix C) by Beck, Weissman, Lester, and Trexler (1974), offered another assessment device to educators. XThe HS consisted of 20 questions to assess a teenager's outlook on the future. The HS was developed using 294 hospitalized 
patients who had made past suicide attempts. A score of zero to one was assigned to each statement. The 11 true statements were assigned zero if the patient answered them negatively, and a one if the patient answered them positively. The nine false statements were assigned a zero if answered positively and a one if answered negatively. The closer to a score of 20 , the greater the suicidal risk. Akazdin, French, Unis, Esveldt-Dawson, and Sherick (1983) conducted an experiment with the HS as assess the degree of hopelessness experienced by the subjects. Whe results indicated the HS was a satisfactory device for assessing hopelessness in children, which may be an indicator of suicide. Educators used the HS to assess the degree of hopelessness a teenager was experiencing and move to an intervention if one was necessary. An assessment scale was used by First CaAl for Help (La Crosse Iutheran Hospital) (Appendix D) for incoming calls which were suicldal in nature. The scale consisted of 19 items where a zero, one, or two were assigned to the responses given by the caller. A score of 15 or higher was considered to be high lethality and called for an immediate intervention, such as calling the police and having them sent to the residence of the suicidal caller. Once again, the teacher used this scale to assess the degree of lethality a teenager was experiencing.

McBrien (1983) offered a list of 10 questions developed by researchers at the Center for Cognitive Therapy (Appendix E). Educators asked these questions of teenagers who are exhibiting 
suicidal symptoms. Examples of the questions were: (a) how will you commit suicide?; (b) do you have a plan?; (c) what has happened that makes life not worth living?; and $(d)$ when you are thinking of sulcide, how long do these thoughts stay with you? 
Chapter III

Interpretation of Iiterature Review

The findings of the Ilterature review were that a number of researchers agree that depression was the major cause of adolescent suicide. Studies cited showed that a majority of subjects had severe depression at the time of serious suicide contemplation. The reasons for depression were varied, but a number of researchers agreed that severe problems in the home and with the family were the majox causes of severe depression in youths. The relatedness of depression and family relations was a circular problem.

Other factors cited by researchers were poor social relations and school failure. Researchers agreed that depression may be the overriding cause for a youth to experience poor social relations with peers and failure in school. The converse was also cited by reseachers. A teenager who was unable to make satisfactory social relations, and who was not accepted in a peer group, may become severely depressed, and think about suicide as an escape. Youths who set unobtainable goals of academic success may experience depression when these goals are not reached and contemplate suicide.

Educators working with a special population of students must be aware of the possible problems a student may have had with school, peer relations, and parental relations. Many researchers were in complete agreement over observable behavior signs which may indicate 
that a teenager might choose suicide as an escape. Researchers also cited events away from school which have influenced adolescents to attempt sulcide.

Researchers were in agreement about the assessment of lethality. The use of the RFL, HS, and the First Call for Help assessment scales of lethality can help the teacher know if the youth has a plan, or access to a means of carrying out a suicide. This can help the teacher intervene and prevent a suicide immediately, ox plan an intervention strategy if the degree of lethality is not very high. 
Chapter IV

Implications and Action Plan

In this chapter the implications of the research were discussed and an action plan was proposed. The action plan was used for inservice training of teachers concerned with the possibility of sulcide among their students.

The increase in adolescent suicide needed to be addressed by educators. Educators spend the majority of the day with teenagers. This involvement provided an excellent opportunity for teachers to take on some of the responsibility to prevent adolescent suicide. From factors cited in chapters I and II an action plan was proposed which included:

1. A unified school program which addressed the 1ssue of adolescent suicide.

2. An inservice training program for concerned teachers.

3. The use of consultants and referral agencies when the problem has become too serious for educators to handle effectively. School involvement. Those teachers concerned about adolescent suicide have formed a school-wide network to reverse the increase In adolescent suicide. Students were made aware of the network and knew it was available when they needed someone to talk to who would not pass judgement, and who kept all matters discussed confidential unless otherwise instructed to by the teenager. 
If the seriousness of the situation warranted, teachers would contact parents or other professionals. The teenager needed someone who was compassionate and empathetic and who treated the youth with respect (Konopka, 1983; Powers, 1979).

The network of teachers together with the health teacher(s) provided a unit on death and suicide. The realization that sulcidal thoughts may have been shared by others was also a preventative device. There were many films and filmstrips available that discussed the topic of suicide, and proposed ways to cope with suicidal feelings. A sample of titles included:

1. Help Me! The Story of a Teenage Suicide. This film discussed a teenager who had committed suicide and how teachers, family, and friends recalled her acting "strange" before the death (S-L Film Productions, 1976).

\section{Sulcide: It Doesn't Have to Happen. This film depicted} a high school teacher reflecting back to his youth when he thought about killing himself, and how he related to a student who had recently attempted suicide (BFA Educational Media, 1976).

3. Teenage Suicide. The f13m discussed adolescent suicide and myths surnonding it (MTI Teleprograms, 1978).

Inservice training. Teachers who were interested in becoming part of a school-wide network of counselors for youths contemplating sulcide were required to attend a full day inservice training program. Materials that were used and distributed to educators are provided in the appendices. The inservice training is outlined in a flow chart in Figure 1. 
Figure 1

Stages in Development of In-service Training of Concerned Teachers

Related to Adolescent Suicide

Stage 1 - Overview of problem; Current statistics regarding adolescent suicide.

Stage 2 - Discuss causes of adolescent suicider depression, family relations, social relations, and school failure.

Stage 3 - Present overt warning signs.

Stage 4 - Discuss suicidal lethality and present and discuss lethality assessment devices.

Stage 5 - View and discuss films: Help Me! The Story of a Teenage Suicide, Suicide: It Doesn't Have to Happen, and Teenase Suicide.

Stage 6 - "Brainstorm" counseling situations and techinques. Use no-suicide contracts.

Stage 7 - Role-play counseling situations. Introduce and use consultant ist.

Stage 8 - Review causes, overt signs, lethality assessment devices, no-suicide contracts, and consultant list.

Stage 9 - Question and answer period. 
Altemative interventions. If a suicidal youth posed too large of a problem for a teacher, the teenager was referred to community support networks (MCNelly, Shafil, and Schwab, 1977). The educator was made aware of the following:

1. Contacts and referral agencles in the social service agencies of a community, which offered free or low-cost counseling.

2. Private counseling services if the teenager's family could afford these services.

3. Contacts and referral personnel in community hospitals.

\section{Summary Statement}

The research cited in this paper indicated that adolescent suicide is at a high level today. The number of actual completed suicides by adolescents had been increasing each year (Emery, 1982; Hart, 1978; Smith, E. J., 1981). Factors identified by reseachers that contributed to adolescent suicide included: depression; family relations; social relations; and school fallure. Reseachers also identified overt behaviors which have shown to be indicators of suicidal ideation in adolescents (Mickenry, et al., 1980). An action plan was proposed that could be implemented in schools to reverse the increase in adolescent suicide. Along with the action plan, recommendations were made for future research. These recommendations included the effects of chemical abuse on adolescent suicide and research to determine additional techniques to help educators cope with adolescent suicide. 
References

Beck, A. T., Weissman, A., Lester, D., \& Trexler, L. (1974). Measurement of pessimism, the Beck Hopelessness Scale. Journal of Consulting and Clinical Psychology, 42, 861-865. Carlson, G. A., \& Cantwell, D. P. (1982). Suicidal behavior and depression in children and adolescents. Journal of the Amertcan Academy of Child Psychiatry, 21, 361-368.

Emery, P. E. (1983). Adolescent depression and suicide. Adolescence, 18, 245-258.

Gibbs, J. T. (1982). Depression and suictdal behavior among delinquent females. Journal of Youth and Adolescence, 10, 159-167.

Greuling, J. W., \& DeBlassie, R. R. (1980). Adolescent suicide. Adolescence, 15, 589-601.

Grob, M. G., Klein, A. A., \& Esisen, S. V. (1983). The role of the high school professional in identifying and managing adolescent suicidal behavior. Journal of Youth and Adolescence, 12, $163-173$.

Hart, N. A. (1978). How teachers can help suicidal adolescents。 The Clearing House, 21, 369-373.

Help me! The story of a teenage suicide (1976) (Film). Los Angles, CA: S-L Film Productions.

Kazdin, A. E., French, N. H., Unis, A. S., Esveldt-Dawson, K. \& Sherick, R. S. (1983). Hopelessness, depression, and suicidal intent amons psychiatricaliy disturbed inpatient children. Journal of Consulting and Clinical Psychology, 21, 504-510. 
Klagsburn, F. (1977). Preventing teenage suicide. Family Health, 57, $21-22$.

Konopka, G. (1983). Adolescent suicide. Exceptional Children, 49. $390-394$.

Lee, E. E. (1978). Suiclde and youth. Personnel and Guidance Journal, 27, 200-204.

Lutheran Hospital First Call for Help, First Call for Help assessment scale.

McAnamey, E. R..(1979). Adolescent and young adult suicide in the United States. Adolescence, 56, 765-773.

McBrien, R. J. (1983). Are you thinking of killing yourself?: Confronting students' suicidal thoughts. The School Counselor, 31. $75-82$.

McGuire, D. (1982). The problem of children's sulcides: Ages 5-14. International Jourmal of Offender Therapy and Comparative Criminology, 26, 10-17.

McKenry, P. C., Tisher, C. L., \& Christman, K. L. (1980). Adolescent suicide and the classroom teacher, The Journal of School Health, 20, $130-132$.

McNeely, J. D., Shafil, M., \& Schwab; J. J. (1977). The student suicide epidemic. Today's iducation, 66, 71-73. Miller, N. K. (1979). Therefore choose life: Suicide prevention as a humanist dilemma. Couseling and Values, 23, 243-250. Morgan, P. (1981). The counselors role in suicide prevention. Personnel and Guidance Jourmal, 52, 284-286. 
Motto, J. A. (1978). Recognition, evaluation and management of persons at risk for suicide. Personnel and Guidance Joumal, 56, $537-543$.

Nielson, S. L., \& Chiles, J. A. (1983). Reasons for staying alive when you are thinking of killing yourself: The Reasons for Living Inventory. Journal of Consulting and Clinical Psychology, 51, $276-286$.

Peck, K. (1982). Youth suicide. Death Education, 6, 29-47. Pfeffer, C. R. (1981). Suicidal behavior of chilaren. Exceptional Children, $48,170-1.71$.

Pfeffer, C. R., Solomon, G., Plutchik, R., Mizruchi, M. S, \& Weiner, A.

Suicidal behavior in latency-age psychiatric inpatients: A replication and cross-validation. Joumal of the American Academy of Child Psychiatry, 21, 564-569.

Plinkston, J. (1983). Adolescent sulcide: ihat you should know. School \& Cornmunity, 69, 8-9.

Powers, D. (1979). The teacher and the adolescent suicide threat. Journal of School Health, 49,561-563.

Rosenkrantz, A. (1978). A note on adolescent suicide: Incidence, dynamics and some suggestions for treatment. Adolescence, 13, $209-214$.

Shaffer, D. (1982). Diagnostic considerations in sulcidal behavior in children and adolescents. Joumal of the American Academy of Child Psychiatry, 21, 414-416. Shaffer, D., \& Fisher, P. (1981). The epidemiology of suicide in children and young adolescents. Journal of the Amexican Academy of Child Psychiatry, 20, 545-565. 
Smith, D. F. (1976). Adolescent suicides A problem for teachers? Phi Delta Kappan, 52, 539-542.

Smlth, E. J. (1981). Adolescent suicide: A growing problem for the school and family. Urban Education, 16, 279-296.

Statistical Abstracts of the United States (1982-1983) National Data Book and Source Guide, (1983). Washington, D.C.: U.S. Government Documents.

Suicide, It doesn't have to happen (1976) (Film). Santa Monica, CA: BFA Educational Media.

Teenage suicide (1978) (Film). Schiller Park, IL: MTI Teleprograms, Inc. Teenage suicide: A critical issue. (1982). New Jersey Education Association Review, 15, 11-16.

Toolan, J. M. (1962). Suicide and suicidal attempts in children and adolescents. American Joumal of Psychiatry, 118, 719-724. T'winame, B. (1981). No suicide contract for nurses. Joumal of Psychiatric Nursing and Mental Health Services, 19, 11-12. Wenz, F. V. (1979). Sociological comelates of alienation among suicide attempts. Adolescence, 14, 19-29. 


\section{Sigmptoma) Appendix A \\ Overtions Associated with Impending Suicide}

1. A drastic change in the student's personal appeaxance, particularily from good to bad.

2. Somatic complaints - muscle aches and pains, stomachaches, backaches, headaches, diarrhea.

3. Inability to concentrate and problems in judgement and memory.

4. A dramatic shift in quality of school work.

5. Changes in daily behavior and living patterms, such as extreme fatigue, boredom, stammerine and/or decreased appetite.

6. Statements such as, "I want to die".

7. Witing a will, or giving away prized possesions.

8. Behavioral disonders in class.

9. Falling asleep in class.

10. Emotional outbursts compounded with crying or laughter.

11. Inability to sit still.

12. Sudden bursts of energy followed by lethargy.

13. Excessive use of alcohol or drugs.

14. Open signs of mental iliness, such as delusions and hallucinations.

15. A sense of overwhelming guilt and shame.

16. Ioss of friends.

17. Running away from home.

18. Accident proness.

19. Impulsive acting out.

20. Temper tantrums.

21. Self-deprecation. 
Appendix A continued

22. Serious conflict.

23. Ioneliness.

24. Aggression, extermal and inhibited.

25. Excessive risk-taking.

Problems away from school that may be effecting the adolescent

26. The death of a family member, close friend or relative, or pet.

27. The divorce or separation of parents, siblings, or relatives.

28. Personal problems with the law or a family member who is having present difficulty with the law.

29. The marriage of a sibling or remarriage of a parent.

30. Change in residence.

31. The adolescent having trouble with a teacher or teachers or a parent having trouble with his/her own boss at work. 
APPENDICES 


\section{A \\ Appendix \\ Reasons for living Inventory}

Survival and Coping Beliefs

1. I care enough about myself to live.

2. I believe I can find other solutions to my problems.

3. I still have many things left to do.

4. I have hope that things will improve and the future will be happier.

5. I have the courage to face Iife.

6. I want to experience all that life has to offer and there are many expexiences I haven't had yet which I want to have.

7. I believe everything has a way of working out for the best.

8. I believe I can find a purpose in life, a reason to live.

9. I have a love of Iife.

10. No matter how badly I feel, I know that it will not last.

11. Iffe is too beautiful and precious to end it.

12. I am happy and content with my life.

13. I an curious about what will happen in the future.

14. I see no reason to hurry death along.

15. I believe I can learn to adjust or cope with my problems.

16. I believe killing myself would not really accomplish or solve anything.

17. I have a desire to live.

18. I am too stable to kill myself.

19. I have future plans I am looking forward to carrying out.

20. I do not believe that things get miserable or hopeless enough that I would rather be dead.

21. I do not want to die.

22. Life is all we have and is better than nothing.

23. I believe I have control over my life and destiny.

Responsibility to Family

24. It would hurt my family too much and I would not want them to suffer.

25. I would not want my family to feel guilty afterwards.

26. I would not want my family to think I was selfish or a coward.

27. My family depends upon me and needs me.

28. I love and enjoy my family too much and could not leave them.

29. My family might believe I did not love thern.

$x^{y}$

30. I have a responsibility and commitment to my family.

Child-Related Concerms

31. The effect on my children could be harmful.

32. It would not be fair to leave the children for others to take care of. 


\section{A \\ Appendix continued}

33. I want to watch my chlidren as they grow.

Fear of Suicide

34. I am afraid of the actual "act" of killing myself (the pain, blood, violence).

35. I am a coward and do not have the guts to do it.

36. I am so inept that my method would not work.

37. I am afraid that my method of killing myself would fail.

38. I am afraid of the unknown.

39. I an afraid of death.

40. I could not decide where, when and how to do it.

Fear of Sooial Disapproval

41. Other people would think I am weak and selfish.

42. I would not want people to think I did not have control over my life.

43. I am concerned about what others would think of me.

Moral Objections.

44. My religious beliefs forbid it.

45. I believe only God has the right to end a life.

46. I consider it morally wrong.

47. I am afraid of going to hell. 


\author{
(1) \\ Appendix \\ Hopelessness Scale
}

True

2. I might as well give up because I can't make things better for myself.

4. I can't imagine what my life would be like in 10 years.

7. My future seems dark to me.

9. I just don't get the breaks, and there's no reason to believe I will in the future.

11. AlI I can see ahead of me is unpleasantness rather than pleasantness.

12. I don't expect to get what I really want.

14. Things just won't work out the way I want them to.

16. I never get what I want so it's foolish to want anything.

17. It is very unlikely that I will get any real satisfaction in the future.

18. The future seems vague and uncertain to me.

20. There's no use in really trying to get something $I$ want because I probably won't get it.

\title{
False
}

1. I look forwand to the future with hope and enthusiasm.

3. When things are going badly, I am helped by knowing they can't stay that way forever.

5. I have enough time to accomplish the things I most want to do.

6. In the future, I expect to succeed in what concerns me most.

8. I expect to get more of the good things in life than the average person.

10. My past experiences have prepared me well for my future.

13. When I look ahead to the future, I expect I will be happiex than I am now.

15. I have great faith in the future.

19. I can look forward to more good times than bad times. 


\section{Appendix}

\section{First Call for Help Assessment Scale}

1. How specific are the 1deas?

0 - abstract and general thoughts - "I'm thinking about suicide". but no specific events related to suicide as method, place of funeral.

1 - has thought of some specific events or circumstances related to suicide.

2 - has considered many specific acts or circumstances related to suicide.

2. Method

0 - not thought about

1 - possibilities have been considered, but no specific methods picked out

2 - has been definitely chosen

3. The Availability of the Method

0 - has not been purchased, e.go pills not purchased, type of pill not decided, gun not bought

1 - has been obtalned, but not readily available

2 - ready immediately, o.g. the gun is in the house

4. Stage of Plan

0 - nothing ready

1 - about to be put into effect

2 - ready

5. Second Source - (a famlly member or close friend)

0 - no chance of committing suicide

1 - will try under certain conditions

2 - definitely will try

6. Patient's Report of Intent to Commit Suicide

0 - vants to live

1 - isn't sure, waiting to see

2 - wants to die

7. Patient's Attitude Toward Living

0 - gives good reasons

1 - says reasons for dying equal or outwelgh reasons for living

2 - sees no reasons for living

8. Patient's Feelings About His/Her Sulcidal Thoughts

0 - feels negative about them

1 - is in acute distress or ambivalent about them

2 - accepts thern 


\section{0 \\ Appendix continued}

9. Patient's Sense of Control Over His/Her Thoughts

0 - keeps them under control

1 - is afraid he/she will be driven to do something and wants someone to control him/her

2 - no longer makes any attempt to keep suicidal thoughts under control

10. Frequency of Thoughts

0 - Isolated and fleeting

1 - pexiods of persistent thoughts

2 - constant and persistent thoughts

11. Pattent's Pexception of Sources of Help

0 - has numerous and reliable sources of help

1 - sources exist, but are few or unreliable

2 - has nowhere to turn

12. Is the Person Seeking Help?

0 - has not sought help because he/she hasn't felt a need for it

1 - has sought or is seeking help

2 - has not sought help because he/she doesn't want interference with any plans

13. Preparations for Death

0 - none

1 - has thought about them

2 - planned out or written

14. Suicide Note

0 - not thought about

1 - considered but not planned out or written

2 - planned out or written

15. Thoughts About the Future

0 - definite plans

1 - has mentioned vague plans

2 - no plans at all

16. Alcohol and Any Other Drugs

0 - not a drug taker

1 - takes drugs socially

2 - continualiy turning to drugs

17. Prior Attempt

0 - none

1 - any prior attempt

There is no one in this category 


\section{Appendix continued}

18. Causing Another's Death

0 - don't believe

1 - questioning

2 - believe they had a hand in someone's death

19. Special Day

0 - none at all approaching

1 - one approaching

2 - date imminent 


\section{D \\ Appendix \\ MaBxien's 10 Questions}

1. How will you do it?

2. How much do you want to die?

3. How much do you want to live?

4. How often do you have these thoughts?

5. When you are thinking of sulcide, how long do these thoughts stay with you?

6. Is there anyone or anything to stop you?

7. Have you ever attempted suicide?

8. Do you have a plan?

9. On a scale from 1 to 10 , what is the probability that you will kill yourself?

10. What has happened that makes life not worth living?

These questions can be kept on index cards at the teacher's desk.

or memorized, and asked of the student when he/she comes in for counseling. 
Fantasy Relaxation

atjective

To ease the individual into a more complex relaxation activity. This could be a bridge from progressive relaxation to guided imagery.

\section{Freparation}

Deep breathing exercise 1 or 2 , Appendix $c$.

\section{Fracedure}

When you are ready, visualize a small, imaginary opening at the very top of your head, about the size of a dime. Through this small opening are flowing rainbows of colors, pink, yel low, aquamarine, etc., flowing cloud-like as in puffs of smoke. Because they are soft and majestic they carry with them all the tension or tightress you have been experiericing. Let these puffs of soft cloudlike color $f l$ ow in and around your head. Watch them circle effortlessly. As they move with the current of air, they vanish into the atmosphere.

Now ance again imagine that the small opering at the top of your head $i s$ covered with bone, skin and hair.

Focus your attention on your breathing. Breathe slowly and deeply 6 times, in through your nose and out through your mouth.

Proceed to Reality Affirmation Exercise.

(adapted from Williams, unpublished paper) 


\section{APPENDIXE \\ GUIDED IMAGERY RELAXATION EXERCISES}




\section{GUIDED IMAGERY RELAXATI ON EXERCISES}

\section{Resentment Imagery}

The resentment imagery process is rot a way to avoid expressing true feelings by turning them into unnaturally positive images. Father, it is a way to gain insight into one's old hurts to relieve the damaging side effects. This allows the client to deal with feelings effectively and, as a result, to experience less stress and tension. The energy tied Up in resentment can then be redirected toward constructive decisions.

Frocedure

Sit in a comfortable chair, feet flat on the floor, eyes closed.

If rou feel terise or distracted, go through the progressive muscle relaxation technique.

Create a clear picture in your mind of the person toward whom you feel resentment. Picture good things happening to that person. Visualize that person receiving love, or attention, or money, whatever you believe that person would see as a good thing.

Be aware of your own reactions. If you have difficulty visualizing good things happening to that person, it is a natural reaction. It will become easier with practice.

Think about the role you may have played in the stressful scene, and how you might reinterpret the event and the ather person's behavior. Imagine how the situaion might look from the other pierson's point of view.

Be aware of how much more relaxed, less resentful you feel. Tell yourself you will carry this new understanding with you. 
You are now ready to open your eyes and resume your usual activities.

Proceed to Reality Affirmation Exercise.

(Simonton, Matthews-Simonton, and Creighton, 1981)

This exercise may be used whenever the client becames aware of rerunning an unpleasant, painful, or angering episode from the past. It may be months before the client has to use it again, or there may be days when he or she uses it half a dozen times. The client may even wish to use this exercise during an unpleasant experience.

While releasing resentment frees the bady from stress, the individual also gains a sense of accomplishment as the feelings surrounding ofd events begin to change, and the client recognizes a new sense of freedom and control as the client discovers he or she is no longer victimized by feelings. 
Mental Imagery for Setting Goals

By asking the client to set goals, the therapist can help him or her conceptualize and focus on reasons for living, reestati ishing the client's connection with life. It is a war for the client to focus on the things that he or she wants out af life to provide the impetus far the client to achieve these goals. The importance of this self-assertiveness stance is that it runs counter to the attitudes of hapelessmess.

\section{Procedure}

Begin with the pragressive muscle relaxation technique.

Select the goal on which you want to work. In your mind visualize the gaal already met.

Experience the feelings you would have with your goal already met. What would people say to you? What would you be doing? What would you look like? Describe your surroundings. Add as marir details as possitile. See other people who are important to you responding to your achievement.

Look back over ary steps it took to reach your goal. What was the first step? Decide to take some action on this first

step. Feel a sense of accomplishment for achieving each step. Add details about the action steps and your feelings. Be happy and thankful for having reached your goal.

Gradually drift back to the present time.

Reality Affirmation Exercise.

Take action on that first step.

(Simontan: Matthews-simanton, and creighton, 1981)

The mental imagery process can help the client define a goal (or goals) more clearly. At times the mental imagery may reveal barriers to reaching the goal. When this happens, 
encourage the client to openly discuss these barriers.

If the client has difficulty with creating a mental imagery and reaching the goal, it may well be that the client does not believe he or she is capable of meeting the goal. Encourage the client to continue practicing the mental imagery, at least the steps involved.

Each time the client discovers the gaal imagery process interrupted by a negative belief, instruct him or her to stop and balance this with a positive belief. Then have the client return to the imagery and visualize reaching the goal. 
Inner Guide Imagery

Clients are often more responsive to insights achieved in consultation with their Inner Guide than they are to the observations of others (the therapist). In this type of therapeutic exercise the client is taught to establish communicatian with the positive resources of the unconscious because it is believed that the messages from the unconscious, ar self (Inner Guide), are always canducive to the person's welfare and good health.

Simonton and Matthews-Simanton have utilized this... technique with cancer patients as a way of helping them to value self and take more responsibility with the lr own illness. Fatients have reported receiving valuable information and guidance through getting in touch wi th their Inner Guides. Because the Inner Guide is an aspect of their own personality, relying on such a guide is a healthy step toward taking responsibility for their physical and psychological health. Frocedure

Breathing relaxation exercise.

Progressive muscle relaxation exercise.

Visualize a natural setting that gives a feeling of warmth, comfort, peace and serenity. Select a spot from memory or fantasies. Concentrate on the details of the scene. Try to experience it with all your senses, as if you were actually there.

Notice a path emerging rear you which winds toward the horizon. Sense yourself walking along this path. It is pleasant and $1 \mathrm{ight}$. 
Notice that in the distance there is a radiant blue-white glow which is moving slowly toward you. There is nothing threatening about the experience.

As the glow cames closer, you realize it is a living creature - an unknown person or a friendly animal.

As the person or creature comes closer, be aware of the details of its appearance. Is the creature masculine or feminine? See its shape and form as clearly as you can. If your guide is a person, notice details of face, hair, eyes, bane structure, tuild.

If this person or creature makes you feel warm, comfortable and safe, you know it is an Inner Guide. Engage the person or creature; get acquainted. Discuss rour problems as you would with a very close friend.

Pay careful attention to any information you receive. from your quide. It may come in the form of conversation or through symbolic gestures, such as the guide's pointing toward something or producing an object that represents its advice.

Establish an agreement with your guide about how to make contact for future discussions.

Then, when you are ready, let your consciousness come back slowly inta the room where your are sitting ar lying down.

Reality Affirmation Exercise.

(Simonton, Matthews-Simanton, and Creighton, 1981)

The client should not be discouraged if contact with the Inner Guide is not made at the first attempt. It is not unusual to take several attempts before reaching successful contact.

The Inner Guide is a part of self that often daes not receive much attention. Getting in touch with the Inner Guide could help the client learn much about his or her feelings, motivations and behavior. 


\section{Mental Imagery for Managing Pain}

Pain is caused by emotional stress as well as actual

phrsical disease or dysfunction. In order to deal with paing,

toth aspects must be considered.

Pain is so often linked closely to tension and fear that

many people are capable of feeling a decrease in pain after

beginning to use relaxation mental imagery on a regular basis.

The client will learn to visualize the body's healing

capabilities and to communicate with the pain and picture it.

This makes the body an active participant, fulling tage ther

its resources to deal with the abnormality.

Procedure

Frepare the client by doing the progressive muscle relaxation activity.

Focus on the pain. Describe its color, shape and size

clearly. It may be a bright red ball or a clouded mass of

gray or a white cube (whatever). It may be the size of a ping pong ball or grapefruit size.

Mentally place the ball or claud out in space, possibly 10 feet away from the body. Make the ball (cloud, cube) bigger, about the size of a baskettall. Then shrink it to the size of a pea. Now let it become whatever size it chooses to be. Usually it returns to the original size visualized.

Begin to change the object's color: make it yellow, then green. Now take the green object and put it back where it was originally seen. At this point, notice whether or not the pain has been reduced.

Reality Affirmation Exercise.

(Simonton, Matthews-Simarion, and Creighton, 1981) 


\title{
MUSIC AS AN AID TO RELAXATION
}

\begin{abstract}
Almost all people in any given society can relate to some trpe of music as a means of conveying feelings. Appropriate mood music may be used with any of the relaxation exercises to entiarice the atmosphere of relaxation. Following is a list of music compiled by Williams (unpublished paper) that can be used for this purpose. The practitioner is encouraged to use any music he or she feels the client will respond tom trot it is suggested that instrumental music is preferable, as vacal music can distract people as they focus on the words.
\end{abstract}

\section{MUSIC: SUGGESTIONS}

Srrtonic Research, Inc.

Wind in the Trees/Heartbeat Wood-masted Sail boat/Country Stream Thunderstorm/Gentle Kain in a Pine Forest Pacific Ocean/Caribbean Lagoon

\section{Complete Records}

Paul Horn, Inside the Great Pyramid, Mushroom Records Debussy, Afternoon of Faum/Daphnis and Chloe/Clouds, Feasts, Sirens, Columbia ML 5112

Pacheltiel (side 1), Canan in D/Sinfonia in G/Sinfonia in $A$, RCA (Erato) FRLI -5468 
Appendix $F$

No Suicide Contracts

Verbal Contract: Have student repeat statement verbatim;

"I will not kill myself"

Do not accept qualifiable restrictions. If the student wants to set a time Iimit, accept the date, but be sure to renew the contract before it expires.

Written Contract: Have student sign contract and then make copies for both the student and teacher:

I,

Student

date

Teachex 